\title{
Rationale for Endodontic Treatment Failures A Radiographic Evaluation Study
}

\author{
Nokku Praveena ${ }^{1}$,Rangu Deepthi ${ }^{2}$ \\ ${ }^{1}$ Assistant Professor, Apollo Institute Of Medical Sciences\& Research, Department Of Dentistry, Hyderabad. \\ ${ }^{2} J$ unior Resident, Apollo Institute Of Medical Sciences\& Research, Department Of Dentistry, Hyderabad .
}

\begin{abstract}
Aim: The aim of the present study is to evaluate the rationale for failure of endodontic treatments radiographically.

Methods: Radiographic evaluation of fifty patients (86 root canals) with failed endodontic treatment was done. Various reasons for failure of endodontic treatment like dislodged coronal seal, underfilled canals, poor quality of fillings, untreated canals and procedural errors during treatment were evaluated. Chi square test was used to determine statistical analysis between different parameters.

Results: The highest incidence of failure up to $23 \%$ is seen in patients with under filled canals with poor quality of fillings. No statistically significant differences were detected among failed root canals with iatrogenic perforations and loss of coronal restoration. Endodontic failure was most consistent in mandibular molar teeth than maxillary molar teeth. Failed root canals were statistically significant in molar teeth than anterior teeth.

Conclusion : Most of the endodontic treatment failures were associated with under filled canals, poor quality of fillings and poor coronal seal. Procedural errors accounted for less than half of failures. The incidence of failures are more in posterior teeth than anterior teeth.
\end{abstract}

Keywords: endodontic failure, radiographic evaluation, procedural errors, under fillings, endodontic treatment.

\section{Introduction}

In recent years due to significant refinements in the delivery of endodontic services have increased both professional and public expectations for the successful retention of natural dentition. Along with these successful root canal treatments there comes inevitable percentage of non healed and endodontic failures. In majority of endodontic outcome studies the outcome assessment is based on clinical and radiographic measures. The successful outcome is strictly defined by complete absence of clinical signs and symptoms and radiolucency. Likewise "failure" has variable definitions. It has been defined in some studies as a recurrence of clinical symptoms along with the presence of a periapical radiolucency ${ }^{[1]}$. The main factors associated with the endodontic treatment failures are persistence of bacterial infection in the canal space and or the periradicular area and presence of preoperative rarefaction. ${ }^{[2]}$ Persistence of bacteria in isthmuses,ramifications and dentinal tubules may evade disinfectants. Treatment is more likely to fail in these teeth with pretreatment periradicular rarefactions than those without these radiographic changes ${ }^{[3]}$

According to YL Ng, Gulabivala non surgical root canal treatment is diagnosed based on the following clinical and radiographic criteria. The presence of clinical signs and symptoms, enlargement of existing periradicular radiolucent lesion, development of new periradicular lesion associated with the tooth and persistence of the lesion at least for 4 years post root canal treatment.

Procedural errors are directly implicated in the failure of root canal treatment. Rotary instruments tend to fracture in the canals when either laws of access cavity preparation are not adhered to or guidelines regarding the use of rotary instruments are not followed. The stage of instrumentation at which the instrument breaks can have an effect on the prognosis. The disinfection and obturation of the part of canal distal to the fractured instrument becomes difficult possibly leading to the presence of persistent infection in that area Ledges, transportations, perforations, missed and blocked canals affect the final outcome of root canal treatment ${ }^{[4]}$

Another factor which is of colossal importance for the success of root canals is the quality of obturation. Success rates are naturally lower for obturations which are under or overextended and are highest for those which end flush or within $2 \mathrm{~mm}$ of the apex ${ }^{[5] .}$ In the presence of an existing periradicular lesion, an overextended root canal filling will have a worse prognosis than a tooth without excess filling material In addition a well-sealing coronal restoration is essential after the completion of obturation as it would prevent the ingress of any microorganisms, which are present in the ambient environment. An impervious seal at the coronal area is vital for a successful prognosis of an endodontically treated tooth ${ }^{[.6]}$ The rationale of failure of root canals is multifactorial and hence this present study evaluates the possible root causes for endodontic treatment failure using radiographic methods. 


\section{Materials And Methods}

A total of 50 patients were included in this cross sectional study. The age group chosen for this study is twenty to sixty years. This study was carried out in Apollo institute of medical sciences and research institute from December 2016 - February -2017. Ethical clearance was obtained from the ethical clearance committee and informed consent was procured from the patients reporting to the department of endodontics. Medical and dental history of the patients was obtained. The inclusion criteria are patients with good oral hygiene, root canal treatment done previously not more than two years, positive tenderness on percussion, matured apices of teeth /tooth treated. The exclusion criteria are patients who discontinued treatments in between, fractured teeth, non restorable teeth and periodontally compromised teeth. Patients with diabetis and steroid therapy were excluded from the study. The quality of fillings, coronal seal, procedural errors like perforations and instrument separation and radiographic pathosis post endodontic treatment was evaluated with the help of panaromic radiographs and intra oral periapical radiographs. The affected tooth and canals in particular and possible problem with the treatment were recorded for all the patients. The root canal filling above radiographic apex of about more than $2 \mathrm{~mm}$ is considered as overfilling. Non homogenous fillings were considered as poor quality fillings. All the type of perforations were considered as iatrogenic perforations. Presence of separated instrument was detected.

\section{Statistical Analysis}

\section{Results}

The chi square test was used for statistical evaluation of the results. A P value $\leq 0.05$ was considered statistically significant. The total number of failed canals were 86. Twenty root canals were failed because of under fillings and poor quality of fillings. Improperly filled canals were seen in mesiobuccal canals in maxillary molars more predominantly.

\begin{tabular}{|c|c|c|c|c|c|c|c|}
\hline Tooth type & Failed canals & $\begin{array}{l}\text { Under } \\
\text { obturated, } \\
\text { poor quality } \\
\text { fillings }\end{array}$ & $\begin{array}{l}\text { Over filled } \\
\text { canals }\end{array}$ & $\begin{array}{l}\text { Dislodged } \\
\text { coronal } \\
\text { seal }\end{array}$ & $\begin{array}{l}\text { Broken } \\
\text { instrume } \\
\text { nts }\end{array}$ & $\begin{array}{l}\text { Iatrogeni } \\
\text { c } \\
\text { peroratio } \\
\text { ns }\end{array}$ & $\begin{array}{l}\text { Untrea } \\
\text { ted } \\
\text { canals }\end{array}$ \\
\hline $\begin{array}{l}\text { Max-15 } \\
\text { anteriors }\end{array}$ & $15(17.4 \%)$ & $08(53.3 \%)$ & $03(20 \%)$ & $02(13.3 \%)$ & $\begin{array}{l}02(13.3 \% \\
)\end{array}$ & $0(0 \%)$ & $0(0 \%)$ \\
\hline $\begin{array}{l}\text { Max -05 } \\
\text { premolars }\end{array}$ & $08(9.3 \%)$ & $02(25 \%)$ & $01(12.5 \%)$ & $05(62.5 \%)$ & $0(0 \%)$ & $0(0 \%)$ & $0(0 \%)$ \\
\hline $\begin{array}{l}\text { Max -12 } \\
\text { molars } \\
\end{array}$ & $20(23.2 \%)$ & $05(25 \%)$ & $01(05 \%)$ & $0(0 \%)$ & $03(15 \%)$ & $03(15 \%)$ & $\begin{array}{l}08(40 \\
\%) \\
\end{array}$ \\
\hline $\begin{array}{l}\text { Mand -03 } \\
\text { anteriors }\end{array}$ & $03(3.4 \%)$ & $02(66.6 \%)$ & $0(0 \%)$ & 01(33.3\%) & $\mathbf{0 ( 0 \% )}$ & $0(0 \%)$ & $0(0 \%)$ \\
\hline $\begin{array}{l}\text { Mand-06 } \\
\text { premolars }\end{array}$ & $06(6.97 \%)$ & $03(50 \%)$ & $0(0 \%)$ & $01(16.7 \%)$ & $\mathbf{0}(0 \%)$ & $\begin{array}{l}02(33.3 \% \\
)\end{array}$ & $0(0 \%)$ \\
\hline $\begin{array}{l}\text { Mand-19 } \\
\text { molars }\end{array}$ & $34(39.5 \%)$ & 08(23.5\%) & $02(5.8 \%)$ & $05(14.7 \%)$ & $\begin{array}{l}10(29.4 \% \\
)\end{array}$ & $\begin{array}{l}06(17.6 \% \\
)\end{array}$ & $\begin{array}{l}02(5.8 \\
\%)\end{array}$ \\
\hline
\end{tabular}

The percentage of failed canals with under obturated and poor quality fillings is $23 \%$, followed by broken instruments which accounted for $15 \%$. The failed canals with loss of coronal seal were about 14\%.Perforations and untreated canals responsible for endodontic treatment failure were about $13 \%$.Only $4 \%$ of root canals failed because of over fillings. No statistically significant differences were seen with the canals failed with poor coronal seal and iatrogenic procedural errors.

The results showed that statistical significant differences were seen among under filled groups and over filled groups. Failed canals were mostly seen in mandibular molars which is about $39 \%$ when compared to maxillary molars with $23 \%$. Operator procedural errors were about $41.1 \%$ in this study.

\section{Discussion}

The success or failure of the root canals is determined by pre operative, intra operative and post operative factors. Significant intra-operative factors include iatrogenic perforation patency at apical terminus and extrusion of root fillings. Significant post-operative restorative factors included presence of cast restoration versus temporary restoration presence of cast post and core, proximal contacts with both mesial and distal adjacent teeth and terminal location of the tooth. ${ }^{[7]}$

Traditionally, three aspects are associated in the analysis of RCT success - the clinical, radiographic and microscopic characteristics. In the clinical context, two of these aspects normally guide the decision-making process: clinical history (symptoms - absence; sensitivity, discomfort and/or pain; physical exam - normality; edema, fistula, excessive mobility) and interpretation of images (signs of periapical health; periapical bone radiolucency.[8,9,10]. Hence in this study radiographical evaluation of failed root canals was done and data was interpreted 
In this present study the failed root canals are characterized by the presence of under filling and poor quality of fillings. Extruded fillings and iatrogenic perforations were also found to have predominant influence on root canal failure. The density and homogenisity of the obturated canals was found to be inadequate in many cases.

However intra oral periapical radiographs are two dimensional depiction of three dimensional structures and the superimposition of anatomic structures makes interpretation of radiographs difficult. This could be a limitation of this study.

A high rate of failure is associated with endodontically treated teeth associated with Apical periodontitis, overfilling, and teeth that were not properly restored after endodontic treatment according to Holland R, Nery MJ, Mello W, Souza V, Bernabé PFE etal in 1979 and the results of the present study were consistent with this findings ${ }^{[11]}$

Meta analysis of root canal treated teeth survival by Y.-L. Ng, V. Mann\& K. Gulabivala ${ }^{[7]}$ revealed that non-molar teeth were associated with significantly higher survival proportions. The results of the present study complimented this literature. Maximum endodontic failures are seen with mandibular molar teeth and the maxillary molar teeth than anterior teeth in the study. The reasons could be the highest incidence of caries, early eruption time and incidence of more pulpal pathologies in molars. In addition the challenging root canal anatomy and extra canals and knowledge of the operator influence the treatment success. The presence of proximal contacts and the terminal teeth also influence the success of root canals in molar teeth as unfavourable distribution of occlusal force and stresses on the terminal teeth would be more ${ }^{\text {.7] }}$

In addition to this the success ratio of the teeth with periapical rarefaction prior to start of treatment is less when compared to teeth without any lesion prior to start of treatment ${ }^{[5]}$. This parameter was not included in the study as diagnostic radiographs are not available with all the patients participated in the study. The patients underwent treatment with different dental practioners.

The apical extent of the filling whether it is flush with the apex or short filling or long fillings were radiographically evaluated in this study. The data revealed that under obturated canals (short of more than $4 \mathrm{~mm}$ from apex.)were having high failure rate than over filled canals, the quality of fillings with or with out voids does have a significant effect on the failure of root canals in this study.

Study of Barrieshi Nusair KM , Al-Omari and AlHiyasat also evaluated the radiographic technical quality of root canal treatment performed by dental students and the results showed that more number of underfilled canals are present than over filled canals in the study. ${ }^{[12]}$

Kojima et al. determined the influence of factors such as apical limit, and pulpal and periapical status on endodontic prognosis using a meta-analysis. Root canal filling within $2 \mathrm{~mm}$ of the radiographic apex appeared as the best prognosis. This fact was considered as a justification for the presence of underfilling more than $2 \mathrm{~mm}$ short of the root apex ${ }^{[13]}$.

A study done by Ricucci D, Langeland K in 1998 revealed that sealer and/or the gutta-percha when extruded into the periapical tissue, the lateral canals and the apical ramifications, there was always a severe inflammatory reaction including a foreign body reaction despite a clinical absence of pain ${ }^{[14]}$ This emphasizes the importance of over fillings on the endodontic treatment outcome .

The other parameter tested in this study is the presence of coronal restoration. Teeth restored with a permanent restoration were associated with significantly higher survival than their counterparts according to Lazarski et al. 2001, Dammaschke et al. 2003, Lynch et al. 2004 ${ }^{\left[\mathbf{7}^{15]}\right.}$ In this study loss of coronal restoration was attributed to dislodged crowns, decementation, fracture of tooth, dislodged temporary restorations, poor quality of permanent restorations and poor crown to root ratio. The inter-relationship between tooth morphological type, the amount coronal tooth structure lost after treatment and the type of final restoration is directly proportional to the survival rate of tooth post endodontic treatment ${ }^{[15]}$

Operative procedural errors (OPE) are caused by several factors inherent to patient and/or professional and their consequences may influence on prognosis ${ }^{\left[{ }^{[16]}\right.}$ The incidence of procedural errors like strip and furcal perforations was evaluated radiographically in this study. The main reasons behind the occurrence of root perforations are calcified canals, excessive removal of coronal dentine, overzealous preparation of root canals, stiff instruments used in curved canals, transportation of canals away from blockages and ledges. Attempt to locate hidden canals and pathologic resorption can cause perforations.

Broken instruments like hand files, protaper rotary files were seen in few failed canals in this study. Poor filling quality and stage of disinfection at the time of separated instrument clearly have influence on success of endodontic treatment. Most of radiographs illustrated calcified canals with broken instruments in this study. Errors characterize disability, non-observance of therapeutic protocol and low level of knowledge involving the endodontic principles. Deficient attendance may be responsible for severe consequences and sequels, which impairs the prognosis, and may jeopardize the quality of root canal done. ${ }^{[10]}$

Untreated canals or missed canals were seen in this study. Mesio buccal canals were missed in all maxillary molars and the causes might be due to inadequate access cavity preparation and poor knowledge of 
operator about root canal anatomy. Most of the untreated canals in mandibular molars are mainly distal canals. Nevertheless the limitation of the present study is use of radiographs for evaluation of failure of root canal treatments. CBCT and histology should have been more specific for the evaluation of success/ failure of endodontic treatment. CBCT increases the potential for evaluating the therapeutic protocol. CBCT scans give the possibility of a reading by mapping, with the acquisition of valuable information through a dynamic display in different planes ${ }^{[17,18]}$.

\section{Conclusion}

Within the limitations of the study, this study concludes that the failure of root canals is mostly attributed to under filled canals and procedural errors during root canal preparation. The proportion of canals with poor coronal restoration was also contributory factor for root canal failure. Thorough knowledge about the root canal anatomy, complexities, proper selection of cases and meticulous adherence to steps in root canal preparation is essential for success of endodontic therapy.

\section{Acknowledgement}

The author would like to thank the management of Apollo hospitals for conduction of this research. The author would also thank the patients who participated in this study. Special mention to head of department for timely suggestions and improvising the study design.

\section{References}

[1]. Ashley M, Harris I. The assessment of the endodontically treated tooth. Dent Update. 2001;28:247-52

[2]. Lin LM, Skribner JE, Gaengler P. Factors associated with endodontic treatment failures. J Endod. 1992;18:625-7.

[3]. Lin LM, Pascon EA, Skribner J, Gängler P, Langeland K. Clinical, radiographic, and histologic study of endodontic treatment failures. Oral Surg Oral Med Oral Pathol. 1991;71:603-11.

[4]. Kerekes K, Tronstad L. Long-term results of endodontic treatment performed with a standardized technique. J Endod. 1979;5:8390.

[5]. Swartz DB, Skidmore AE, Griffin JA. Twenty years of endodontic success and failure. J Endod. 1983;9:198-202

[6]. Bayram HM, Celikten B, Bayram E, Bozkurt A. Fluid flow evaluation of coronal microleakage intraorifice barrier materials in endodontically treated teeth. Eur J Dent. 2013;7:359-62.

[7]. $\mathrm{Ng} \mathrm{YL,} \mathrm{Mann.V,} \mathrm{Gulabivala.K.A} \mathrm{prospective} \mathrm{study} \mathrm{of} \mathrm{the} \mathrm{factors} \mathrm{affecting} \mathrm{outcomes} \mathrm{of} \mathrm{non-surgical} \mathrm{root} \mathrm{canal} \mathrm{treatment:} \mathrm{part} \mathrm{2:}$ tooth survival. Int Endod J 2011; Jul;44(7):610-25.

[8]. Dr. Sadashiv Daokar, Dr.Anita.Kalekar endodontic failures- a review.IOSR-JDMS 2013;4(5): 05-10.

[9]. Sadia. Tabassum, Farhan Raza Khan. Failure of endodontic treatment: The usual suspects. Eur J Dent 2016;10(1):144-147.

[10]. Carlos Estrela. Roberto Holland. Cyntia Rodrigues et al. Characterization of Successful Root Canal Treatment. Braz Dent J.2014;25(1).

[11]. Holland R, Nery MJ, Mello W, Souza V, Bernabé PFE, Otoboni-Filho JA. Root canal treatment with calcium hydroxide II: effect of instrumentation beyond the apices. Oral Surg Oral Med Oral Pathol 1979;47:93-96.

[12]. Barrieshi-Nusair KM, Al-Omari MA, Al-Hiyasat AS. Radiographic technical quality of root canal treatment performed by dental students at the Dental Teaching Center in Jordan. J Dent 2004;32(4):301-307.

[13]. Kojima K, Inamoto K, Nagamatsu K, Hara A, Nakata K, Morita I, et al.. Success rate of endodontic treatment of teeth with vital and nonvital pulps: a meta-analysis. Oral Surg Oral Med Oral Pathol Oral Radiol Endod 2004;97:95-9.

[14]. Ricucci D, Langeland K. Apical limit of root canal instrumentation and obturation, part 2. A histological study. Int Endod J 1998;31(6):394-409.

[15]. Ng YL, Mann.V, Gulabivala.K. Tooth survival following non-surgical root canal treatment: a systematic review of the literature. Int Endod J 2010;43(3):171-89.

[16]. Silva JA, de Alencar AH, da Rocha SS, Lopes LG, Estrela C. Three-dimensional image contribution for evaluation of operative procedural errors in endodontic therapy and dental implants. Braz Dent J. 2012;23(2):127-34.

[17]. Moura MS, Guedes OA, Alencar AHG, Azevedo B, Estrela C. Influence of length of root canal obturation on apical periodontitis detected by periapical radiography and cone beam computed tomography. J Endod 2009;35:805-809.

[18]. Cotton TP, Geisler TM, Holden DT, Schwartz SA, Schindler WG. Endodontic applications of cone-beam volumetric tomography. J Endod 2007;33:1121-1132. 